\title{
Hydrothermal Activity in the Pacific and Atlantic Ocean - How Noble Gases Can Help to Identify Different Regimes of Hydrothermal Transport in Ocean Sediments
}

\author{
EDITH HORSTMANN ${ }^{1}$, DR. YAMA TOMONAGA ${ }^{2}$, \\ MATTHIAS BRENNWALD ${ }^{3}$, VOLKER LIEBETRAU ${ }^{4}$, \\ MARK SCHMIDT $^{4}$ AND ROLF KIPFER ${ }^{1}$ \\ ${ }^{1}$ Eawag \\ ${ }^{2}$ Eawag, Swiss Federal Institute of Aquatic Science and \\ Technology \\ ${ }^{3}$ Swiss Federal Institute of Aquatic Science and Technology \\ (Eawag) \\ ${ }^{4}$ GEOMAR Helmholtz Centre for Ocean Research Kiel \\ Presenting Author: edith.horstmann@eawag.ch
}

We present noble gas (NG) concentrations in deep-sea sediment pore fluids obtained from the northern Guaymas Basin in the vicinity of a recently discovered active black smoker field [1]. Concentrations of $\mathrm{Ne}, \mathrm{Ar}, \mathrm{Kr}$ and Xe suggest,

1. that in a distance of about $100 \mathrm{~m}$ from the hydrothermal vent system, pore fluids of the pelagic sediment are originating solely from overlying ocean water, which is incorporated into the sediment column during sedimentation, and

2. that no (diffusive or advective) transport of hydrothermal fluids takes place in the pelagic sediment body surrounding the smokers. This leads to the conclusion, that hydrothermal fluid transport from the Mid-Ocean Ridge Basalt (MORB) source feeding the hydrothermal system to the smoker chimneys takes place in very narrow pathways.

Increased ${ }^{3} \mathrm{He} /{ }^{4} \mathrm{He}$ ratios from presumably 5 ky ago preserved in the sediment pore space suggest that during the early evolutionary stages of the vent system, fluid transport was stronger and modulated by the formation of gas bubbles.

NG data from deep-sea sediments from a second sampling campaign around the Azores archipelago prove the presence of hydrothermal fluids in the pore space of these sediments. Helium isotope ratios suggest that the MORB source feeding the hydrothermal system in the northern Guaymas Basin in the Pacific Ocean has a very similar isotope signature to the source causing the hydrothermal activity around the Azores archipelago in the Atlantic. However, while in the Guaymas Basin only localized and focussed transport of hydrothermal fluids through the black smoker chimneys can be observed (i.e. the surrounding sediments do not seem to participate in transport), in the Azores region the opposite seems to be the case: He profiles hint to a diffuse upwelling of hydrothermal fluids in the pelagic sediment body, possibly in large areas across the ocean floor.

[1] Berndt et al. (2016), Geology, 44, 767-777 